\title{
MODERATING IMPACT OF SUPERVISOR SUPPORT ON KNOWLEDGE SEEKING INTENTION OF INTERNATIONAL STUDENTS: A CONCEPTUAL FRAMEWORK
}

\author{
Waqas Khuram ${ }^{1 *}$, Yanqing Wang ${ }^{2}$ and Aisha Khalid ${ }^{3}$ \\ ${ }^{1}$ Waqas Khuram School of Management, Harbin Institute of Technology, Harbin China, \\ waqaskhuram@hit.edu.cn \\ ${ }^{2}$ Prof.Yanqing Wang School of Management, Harbin Institute of Technology, Harbin China, \\ yanqing@hit.edu.cn \\ ${ }^{3}$ Aisha Khalid, School of Management, Harbin Normal University, Harbin China, \\ aishakhuram.19@gmail.com \\ "Corresponding Author
}

\begin{abstract}
The paper integrates the theory of planned behavior concepts, attitude, subjective norms, self-efficacy directly related to knowledge-seeking intention, and it further proposes the moderating role of the supportive supervisor in the relationship with attitude, subjective norms, self-efficacy directly related to the knowledgeseeking intention of international students within Chinese academic settings. The higher educational institution globally trying to attract the educational aspirants and offer a quality of education with a conducive environment to provide academic support that may increase their behavioral intention. Archival study in which references from books, journals, and other studies have been obtaining to develop propositions.
\end{abstract}

Keywords: Attitude, Subjective norms, Knowledge-seeking intention, Supervisor support, International students

\section{INTRODUCTION}

Global modernization and the emergence of the knowledge-based economy have compelled all countries to raise spending in education, training, research, and innovation to succeed in foreign markets. Therefore, higher education institutions (HEIs) have become an essential source of information for developing, exchanging, and incorporating students into internationalization initiatives (Garson, 2016). In order to entice international talent, higher education institutions offer numerous scholarships. In turn, a research-based learning forum and environment stimulate students' interest and intention to seek knowledge by engaging and contributing to knowledge advancement within the supporting mechanism (Fan et al., 2019; Shin et al., 2018). In comparison, the Chinese government allocates large educational budgets on the Western model and provides financial assistance and research scholarship to draw domestic and foreign university students (Wen et al., 2018). Therefore, HEls are highly concerned and focused on quality education for their students, which contributes to an increasing departmental dedication to enhancing learning through the implementation of numerous policies and programs to improve students' academic success.

However, during their academic period, students' performance, including learning, high grades by improved qualifications and competition in potential career and market demand after graduation, also demonstrates 
institutes' quality and performance. Empirical literature and educational researchers demonstrated that an individual's knowledge-seeking intention is influenced by several factors, including personal, behavioral, social, environmental, and socio-economic. In addition to their vital position in developing and distributing information, several higher education institutions create a conducive and supportive learning atmosphere for students to influence and increase their behavioral intention toward learning. In similar studies by (Fan et al., 2019; Khuram et al., 2017), founds that the supervisor's role is also one of the factors that have an impact on student outcomes; they further argued that literature related to the supporting role of Chinese professors in supervising international students in Chinese research-oriented degree programs are limited. Much of the research conducted by western countries has been explicitly focused on supervisors' role in PhD students' experience, with extensive evidence for supervisor influence not only on performance but completion program timely.

\subsection{Theoretical Background and Propositions}

Based on and theory of planned behavior (Ajzen, 1991), this research proposes a framework with the students' academic attitudes, subjective norms, and academic self-efficacy directly related to knowledgeseeking intentions. We further propose that supervisory support moderates the relationship between knowledge-seeking intentions and academic attitudes, subjective norms, academic self-efficacy. In forecasting a diverse variety of behaviors and actions, TPB has been commonly used. TPB's theoretical assumptions indicate that attitudes, subjective norms, and perceived behavior control (efficacy) are the main antecedents that directly influence and shape a person's behavioral intention (knowledge seeking).

\subsubsection{Knowledge-Seeking Intention}

Students are seeking knowledge and develop the expertise to resolve their knowledge gaps. The intention to pursue knowledge is the degree to which one assumes that one should engage oneself in a specific method or process to obtain knowledge (Ajzen, 1991). According to Yu et al. (2018), knowledge-seeking through informational text is requisite to attain a deep and empowering sense of self that can help define one's goals, sustain interest, and allow for self-determination. Sharma and Bock (2005) examined that behavior can influence people's intentions towards knowledge seeking. Likewise, research on information and knowledgeseeking suggests that various factors can stimulate individuals' decisions toward seeking knowledge from others (Zhang, 2019). Ajzen (1991) investigated the antecedents of knowledge-seeking from the learning perspective using survey data from a global organization and found perceived intellectual demand and learning orientations conducive to higher knowledge-seeking behavior levels.

Furthermore, Leonardi and Neeley (2017) indicate that knowledge-seeking is a behavior that enhances knowledge and leads to accomplishing tasks independently. Within a non-academic context, seeking knowledge is also a need-driven behavior in which employees are motivated to seek knowledge from external sources when they encounter problems beyond their knowledge (Khuram \& Wang, 2018). With access to acquire knowledge from other sources, employees can better accomplish more complex tasks and make decisions effectively. These problem-solving skills can enhance an individual's knowledge-seeking behavior, which essentially reflects the instrumental purpose of organizational activities in accomplishing tasks, improving performance, and obtaining promotions and rewards. Individual knowledge-seeking behavior in higher education is a relatively new field of research.

\subsubsection{Attitude towards Knowledge-Seeking}

Attitudes are psychological orientations based on one's own experiences, beliefs that affect one's understanding of situations and events, and how one might react positively or negatively (Allport, 1935). It has long been established as one of the most important social psychology constructs (Allport, 1935). Accordingly, Steele-Johnson et al. (2013) define educational attitude as an individual educational behavior toward any academic activity such as learning, seeking, sharing, understanding the knowledge, and performing accordingly. However, research has shown that attitude is a perceptual construct and has a significant effect on developmental activity, such as educational learning and training (Noe \& Wilk, 1993). More specifically, an individual's attitude toward education reflects his or her attitude toward acquiring skills and knowledge through a formal educational process. The favorable (positive) academic attitude of an individual has always been linked with high motivation to attend learning sessions and motivation to learn(Steele-Johnson et al., 2013; Veeravalli et al., 2019).

Attitude is one of the TPB's significant components, typically observed as the strongest predictor of intention. Intentions have been viewed as the "conative component of attitude," It has been assumed that this conative component is related to the attitude's significant component. Several studies have shown that attitudes 
influence the actual seeking intention (Veeravalli et al., 2019). These behavioral beliefs are major cognitive determinants of students' behavioral intentions and their actual behavior. Accordingly, behavioral intention to perform a behavior is a function of attitude toward performing the behavior (Romano \& Netland, 2008). Attitude consists of both beliefs about a behavior's consequences as well as an evaluation of those consequences. For example, if a student believes that seeking knowledge from any sources to perform better is not wrong, or that the consequences are not severe, it is more likely that the intention to seek knowledge will be higher. Conversely, if a student holds the belief that seeking is wrong, or that the consequences are severe, it is more likely that the intention to seek knowledge will be lower. Thus on the bases of the above, we propose that

Proposition 1: attitude toward knowledge-seeking will be positively associated with knowledge-seeking intention

\subsubsection{Subjective Norms}

Subjective norm is another determinant that correlates with behavioral intention under the TPB framework. Subjective norms in various studies are defined as "a social factor that influences a person's belief" by using the social environment (social groups) (Hussein, 2018). The individual notion is dependent on the people surrounding oneself as to whether one advocated performing certain behaviors. According to Ajzen (1991), these social groups in a social environment play a crucial role as it is assumed to be a function of social pressures on how others think and intervene in a person's decision to perform. Subjective norm is determined to measure the social influences (i.e., family members' and friends') on a person's behavior. However, international students often feel very lonely in their new environment. Such loneliness includes the lack of familiar friends, social networks, familiar cultural and linguistic environments (Sherry et al., 2010), who require social connectedness to perform and succeed in a new environment.

The correlation between subjective norms and behavioral intention has broadly been discussed in research studies (Ajzen, 1991). In several other studies, social groups, such as friends and families, were considered major factors in creating social influences on an individual's intention. With closer investigation, it was found that family was the most influential factor, followed by friends (Hussein, 2018), and positively correlated with each other, significantly affecting university students' intention (i.e., seeking knowledge). The intended behavior will be performed when they have a positive attitude toward it and think that people surrounding them believe they should do so (Hussein, 2018). It means that close ones such as family members and friends can influence a student's behavioral intention towards knowledge-seeking. The well-established literature on social influence determines that others influence a person's beliefs, and behaviors. Subjective norm has received substantial empirical support as an important antecedent to behavioral intention. Thus, we propose that:

\section{Proposition 2: Subjective norm will be positively associated with knowledge-seeking intention}

\subsubsection{Self-Efficacy}

Self-efficacy can be defined as individuals' confidence in performing any academic tasks at a designated level (Caprara et al., 2011). Students need more than just the ability and skills to be successful; they also need a sense of confidence to use their skills and abilities and regulate their learning. Self-efficacy is defined as the "beliefs in one's capability to organize and execute the courses of action required to manage prospective situations." In academic settings, self-efficacy beliefs help to predict results beyond the contributions of ability, previous accomplishments, knowledge, and skill alone. Self-efficacy toward seeking and learning by (Caprara et al., 2011) refers to the individual's academic ability belief, is a subjective judgment of the individual's ability to control and his hold learning behavior toward and academic performance, and is the performance of self-efficacy in the field of learnings. Information or knowledge seeking and academic self-efficacy both constructs have been broadly used in the related literature as important antecedents of academic performance (Azila-Gbettor \& Abiemo, 2020). Information seeking an investigation in educational environments includes numerous theoretical and empirical studies striving to associate individuals' (students, academics, and researchers) behavior toward information with their cognitive and emotional assimilation to the academic environment. Therefore, we propose that

Proposition 3: Self-efficacy will be positively associated with knowledge-seeking intention

\subsubsection{Supervisor Support}

International students of higher education in china are conducting academic research under the authority of the Chinese supervisor. Such supervisors have a vital role in teaching, monitoring, and mentoring students 
to achieve their academic career goals (Fan et al., 2019). According to Zhu et al. (2011), the supervisor's position is similar to that of managers in a non-academic context and plays a significant role in improving employee performance. Similarly, the related research further encapsulated that workers' success (e.g., creativity and innovation) is affected by their managers' supervision style. Supporting supervisors contribute to an organizational culture that allows participants to turn their creative talents into successful results, in addition to addressing personal and cultural concerns and experience in every environment (Wisker et al., 2003). Simultaneously, with the rapidly evolving academic climate, the academic supervisor's position has become more of a manager, while supervisors are the main element in accelerating the learning process (Zhu et al., 2011). As the efficiency, success, and output of doctoral studies are positively affected by the supervisor.

Supervision is a challenging teaching job, beginning as a project manager, and becoming a vital partner (Adedokun et al., 2010). International student supervision is also comparatively more complicated than domestic students, since supervisors know that international students are hard-working and concentrated (Wen et al., 2018). Despite this, many international students rely on their supervisors to learn about their academic achievement and their duties as researchers and provide their academic programs and long-term career ambitions with information and advice. Therefore, Jarvis and Parker (2006) accordingly claimed that postgraduate supervision is an overall system with three key dimensions: institutional, supervisory, and student-related factors. Nonetheless, instructors' guidance and motivation in their behaviors enhance student flexibility and encourage engagement in academic results (Gu et al., 2017). As the quality, progress, and performance outcomes of doctoral studies are heavily influenced by the supervisor

\subsubsection{Supervisor Support as Moderator}

Various research has pointed out that a Supervisor's supportive role in higher learning settings is important in individual students' success and may reduce the negative impact of behavioral intention, norms, and productivity. The supervisor, therefore, attempts to interpret their academic activities and to understand their interest and behavior. Fan et al. (2019) noticed related results that the Chinese supervisors urge their subordinates to improve their commitment and seek information and knowledge. Dysvik and Kuvaas (2013) also found a positive correlation between antecedents of knowledge-seeking intention and supervisor support in doctoral students. Various studies have also analyzed the moderating effects of supervisor supports. Sakurai and Jex (2012) found that supervisor support moderated the relationship between students' work efforts and behavioral emotions and counterproductive behaviors such that the relationship was positive with a high level of supportive behavior of supervisors. Recent research by Adil and Ab Hamid (2020), has shown the correlation between teamwork and employee performance in high technology organizations in Pakistan, as a result of supervisors supporting. Focus on prior studies' results. The argument is also rational that a supervisor should also balance the interaction between academic mind-set, moral expectations, academic integrity, and individuals' desire to pursue information. Henceforward the following propositions are presented.

Propositions 4: Supervisor support will moderate the relationship between attitude and knowledge-seeking intention such that the positive relationship between attitude and knowledge-seeking intention will be higher for those with a high level of support.

Propositions 5: Supervisor support will moderate the relationship between subjective norm and knowledgeseeking intention such that the positive relationship between subjective norms and knowledge-seeking intention will be higher for those with a high level of support.

Propositions 6: Supervisor support will moderate the relationship between self-efficacy and knowledgeseeking intention such that the positive relationship between self-efficacy and knowledge-seeking intention will be higher for those with a high level of support 


\subsection{The Conceptual Framework}

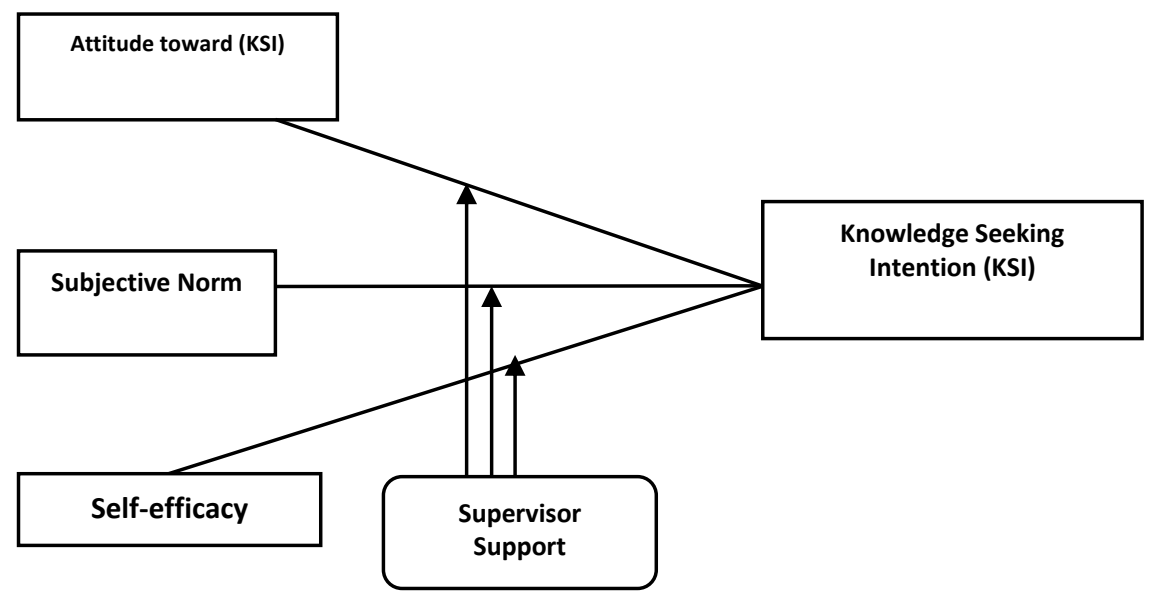

Fig. 1 Conceptual Framework

The conceptual framework is representing the propositions given in figure 1. As shown in the conceptual framework, it proposed that academic attitude, subjective norms, and academic self-efficacy influence knowledge-seeking intention and the relationship between the academic attitude, subjective norms, academic self-efficacy, and knowledge-seeking intention moderated by supervisor support. We recommend this conceptual framework to be tested in future studies.

\subsection{Conclusion and Future Research Implications}

Though the previous researcher has examined and analyzed TPB constructs' relationship in different studies, however, the best of our knowledge, none of the studies has explored the moderating role of supervisor support on the relationship between academic attitude, subjective norms, academic self-efficacy, and knowledge-seeking intention. Based on prior literature and logical reasoning, this study proposed to explore the moderating role of supportive supervisors on the relationship between academic attitude, subjective norms, academic self-efficacy, and knowledge-seeking intention, which was deserted by previous studies. We propose that a positive attitude, support from subjective norms, and students' high academic self-efficacy boost their knowledge-seeking intention. However, supervisor support and encourage supervisees may help increase their learning and seeking intention, leading to better performance despite any academic stress. Future empirical studies ought to conduct to examine whether such propositions are supported and validated by the data or not. If validated, such empirical results may encourage the individual, i.e., academicians, supervisors, students, and even surroundings, to adopt such practices intended to develop a supportive environment to enhance knowledge-seeking behavior in academic settings.

\section{ACKNOWLEDGMENTS}

This research is financially supported by the NATIONAL NATURAL SCIENCE FOUNDATION OF CHINA (Grant NO. 71573065 and Grant NO. 71571085).

\section{REFERENCE LIST}

Adedokun, Omolola A, Dyehouse, Melissa, Bessenbacher, Ann, \& Burgess, Wilella D. (2010). Exploring Faculty Perceptions of the Benefits and Challenges of Mentoring Undergraduate Research. Online Submission.

Adil, Muhammad Shahnawaz, \& Ab Hamid, Kamal Bin. (2020). Effect of Teamwork on Employee Performance in High-Tech Engineering SMEs of Pakistan: A Moderating Role of Supervisor Support. South Asian Journal of Management, 14(1), 122-141.

Ajzen, Icek. (1991). The theory of planned behavior. Organizational behavior human decision processes, 50(2), 179-211. 
Allport, Gordon W. (1935). Attitudes: a handbook of social psychology: Clark University Press, Worcester.

Azila-Gbettor, Edem M., \& Abiemo, Martin K. (2020). Moderating effect of perceived lecturer support on academic self-efficacy and study engagement: evidence from a Ghanaian university. Journal of Applied Research in Higher Education, ahead-of-print(ahead-of-print). doi:10.1108/jarhe-04-20200079

Caprara, Gian Vittorio, Vecchione, Michele, Alessandri, Guido, Gerbino, Maria, \& Barbaranelli, Claudio \%J British Journal of Educational Psychology. (2011). The contribution of personality traits and self-efficacy beliefs to academic achievement: A longitudinal study. 81(1), 78-96.

Dysvik, Anders, \& Kuvaas, Bård (2013). Perceived job autonomy and turnover intention: The moderating role of perceived supervisor support. European Journal of Work Organizational Psychology, 22(5), 563573.

Fan, Luo, Mahmood, Monowar, \& Uddin, Md Aftab. (2019). Supportive Chinese supervisor, innovative international students: A social exchange theory perspective. Asia Pacific Education Review, 20(1), 101-115.

Garson, Kyra. (2016). Reframing internationalization. Canadian Journal of Higher Education, 46(2), 19-39.

Gu, Jibao, He, Changqing, \& Liu, Hefu. (2017). Supervisory styles and graduate student creativity: the mediating roles of creative self-efficacy and intrinsic motivation. Studies in Higher Education, 42(4), 721-742.

Hussein, Zuhal. (2018). Subjective norm and perceived enjoyment among students in influencing the intention to use e-learning. International Journal of Civil Engineering Technology, 9(13), 852-858.

Jarvis, Peter, \& Parker, Stella. (2006). Human learning: An holistic approach: Routledge.

Khuram, Waqas, Bhutto, Arabella, \& Jabeen, Arifa. (2017). Analyzing the Impact of Higher Education Commission Policies on Motivation of the Faculty Member of Jamshoro Education City. International Journal of Academic Research in Business Social Sciences, 7(6), 2222-6990.

Khuram, Waqas, \& Wang, Yanqing. (2018). Sharing Knowledge through Sharing Advisor in Age of Sharing Economy: A Conceptual Model. Paper presented at the 2018 International Conference on Economics, Business, Management and Corporate Social Responsibility (EBMCSR 2018).

Leonardi, Paul, \& Neeley, Tsedal. (2017). What managers need to know about social tools.

Noe, Raymond A, \& Wilk, Steffanie L. (1993). Investigation of the factors that influence employees' participation in development activities. Journal of applied psychology, 78(2), 291.

Romano, John L, \& Netland, Jason D (2008). The application of the theory of reasoned action and planned behavior to prevention science in counseling psychology. The Counseling Psychologist, 36(5), 777806.

Sakurai, Kenji, \& Jex, Steve M. (2012). Coworker incivility and incivility targets' work effort and counterproductive work behaviors: The moderating role of supervisor social support. Journal of Occupational Health Psychology, 17(2), 150.

Sharma, Sanjeev, \& Bock, Gee-Woo. (2005). Factors Influencing Individual's Knowledge Seeking Behavior in Electronic Knowledge Repository. Paper presented at the European Conference on Information Systems.

Sherry, Mark, Thomas, Peter, \& Chui, Wing Hong. (2010). International students: A vulnerable student population. Higher Education, 60(1), 33-46.

Shin, JC, Postiglione, Gerard A, \& Ho, KC. (2018). Challenges for doctoral education in East Asia: a global and comparative perspective. Asia Pacific Education Review, 19(2), 141-155.

Steele-Johnson, Debra, Narayan, Anupama, \& Steinke, Julie. (2013). Academic attitudes and their antecedents. Journal of Applied Social Psychology, 43(3), 498-506. doi:10.1111/j.15591816.2013.01030.x

Veeravalli, Suchitra, Venkatraman, Vijayalakshmi, \& Hariharan, Manoj. (2019). Why do people seek knowledge? Tracing factors that affect knowledge seeking Intention. VINE Journal of Information and Knowledge Management Systems, 50(2), 271-290. doi:10.1108/vjikms-04-2019-0059 
Wen, Wen, Hu, Die, \& Hao, Jie. (2018). International students' experiences in China: Does the planned reverse mobility work? International Journal of Educational Development, 61, 204-212. doi:10.1016/j.jjedudev.2017.03.004

Wisker, Gina, Robinson, Gillian, Trafford, Vernon, Warnes, Mark, \& Creighton, Emma. (2003). From supervisory dialogues to successful PhDs: Strategies supporting and enabling the learning conversations of staff and students at postgraduate level. Teaching in higher education, 8(3), 383397.

Yu, Hongwei, Glanzer, Perry L., Johnson, Byron R., Sriram, Rishi, \& Moore, Brandon. (2018). Why College Students Cheat: A Conceptual Model of Five Factors. The Review of Higher Education, 41(4), 549576. doi:10.1353/rhe.2018.0025

Zhang, Michael Jijin. (2019). Interpersonal feelings and knowledge seeking in China. Asia Pacific Business Review, 26(1), 50-71. doi:10.1080/13602381.2019.1610290

Zhu, Yu-Qian, Chen, Li-Yueh, Chen, Houn-Gee, \& Chern, Ching-Chin. (2011). How does Internet information seeking help academic performance?-The moderating and mediating roles of academic selfefficacy. Computers Education, 57(4), 2476-2484. 